\title{
Water Quality Monitoring and Controlling using IoT
}

\author{
Haziq Lukman Johar ${ }^{1}$, Shamsul Mohamad ${ }^{1, *}$, Shaharil Mohd Shah ${ }^{1}$, Rafizah \\ Mohd Hanifa ${ }^{1,2}$
}

${ }^{1}$ Faculty of Electrical \& Electronic Engineering,

Universiti Tun Hussein Onn Malaysia, Batu Pahat, Johor, MALAYSIA

${ }^{2}$ Centre for Diploma Studies,

Universiti Tun Hussein Onn Malaysia, Batu Pahat, Johor, MALAYSIA

*Corresponding Author

DOI: https://doi.org/10.30880/jeva.2021.02.01.003

Received 20 February 2021; Accepted 06 June 2021; Available online 30 June 2021

\begin{abstract}
The water quality status of rivers in Malaysia has always been a cause for concern for various local authorities, government agencies, and the public. The issue is that the traditional method, such as workers, needs to go to each tank or river to collect data. The process set some drawbacks such as labor-intensive, lack of real-time data, and high operation and equipment costs. In this research, the aim is to implement the Internet of Things (IoT) in monitoring and controlling the water quality. The $\mathrm{pH}$ and temperature sensors were integrated with NodeMCU ESP82666 to collect water $\mathrm{pH}$ and temperature data. This platform is also used to control the servo motor for managing systems. NodeMCU sends the data through the Internet to the Blynk application. Using Blynk, users can monitor live data from the tank, see the data trend, and control the water quality. All the data that has been taken is saved in the cloud database using phpMyAdmin. The connection also used NodeMCU ESP8266, where the coding was written and compiled using Arduino IDE software. This project has successfully achieved its objective where water quality data $(\mathrm{pH}$ and temperature) can be monitored, stored in a database, and water $\mathrm{pH}$ levels can be controlled using IoT.
\end{abstract}

Keywords: Internet of Things, water quality

\section{Introduction}

Water has been provided to humankind as one of the essential natural resources. The water quality status of rivers in Malaysia has always been a cause for concern for various local authorities, government agencies, and the public. Currently, Malaysia has over 1000 manual and automatic water quality monitoring stations in 146 basins maintained by the Department of Environment (DOE), the Department of Irrigation and Drainage (DID), and the respective state-level agencies[1].

Unfortunately, society's development and countless human activities have accelerated pollution and degraded water resources. In March 2019, thousands fell ill after illegal dumping of chemical waste into the Kim Kim River in Pasir Gudang, Johor [2]. Industrial wastewater, mainly from chemical and pharmaceutical production, often contains substances that need to be treated according to Environment Quality (Industrial effluent) Regulation 2009 before discharge [3].

Management of liquid waste focuses on finding a way to dispose of the waste in a safe way for humans and the environment. The impact of not following the regulation is water that has an unbalanced acidity level will cause the environmental health and ecosystem to be disturbed [4]. Traditional water quality methods involve the manual 
collection of water samples at different locations, followed by laboratory analytical techniques to determine the water's character. The process will cause some errors like the worker wrote the wrong data.

\section{Previous Works}

Santoso, L. W., Kwariawan, A., \& Lim, R. propose to design and implement an IoT for the data logger and pH controller [5]. The developed system can interact with a range of smart objects using Wi-Fi, Bluetooth, and Infrared Data Association (IrDA) standard. The apps have some features to add new $\mathrm{pH}$ meters, such as logging in, signing up, and adding a phone number. There is a feature for setting $\mathrm{pH}$ limits per device and setting device information or removing the device. The system also provides a wastewater management solution to know the liquid's acidity level and improve the $\mathrm{pH}$ environment using cutting-edge technology.

Meanwhile, Brinda Das and P.C. Jain developed a system that monitors water quality in real-time through different sensors to measure water quality[6]. Three sensors ( $\mathrm{pH}$, conductivity, temperature), microcontroller module processing, and two Zigbee and GSM data transmission modules are used in this system. In the form of analog signals, the three sensors capture data. Such signals were translated into digital format by the ADC. Such digital signals are sent to the microcontroller through a Zigbee unit. The microcontroller processes, analyses and communicates digital information through the GSM module, which sends an SMS with the water quality parameters to the smartphone or server, displayed on the microcontroller's LCD.

Kamarul Hafiz proposed implementation of the Internet of Things (IoT)-based network by combining the Radio Frequency Identification (RFID) system, the Wireless Sensor Network (WSN) platform and the Internet Protocol (IP)based communication into a single water quality monitoring platform (WQM)[7]. The suggested radio frequency to be installed in the vegetation region is $920 \mathrm{MHz}$ for the planned WSN interaction. In this proposed system, the measured water parameter is the $\mathrm{pH}$ rate using an analog $\mathrm{pH}$ sensor. Throughout $\mathrm{pH}$ analysis, the ambient temperature is measured using an analog temperature sensor.

Gopavanitha \& Nagaraju have designed a low-cost system to track and regulate water quality in real-time using IoT[8]. The system contains physiochemical sensors capable of measuring water's physical and chemical parameters, including turbidity, temperature, conductivity, flow, and $\mathrm{pH}$. These sensors detect water contaminants. The sensor values are stored and sent to the cloud by Raspberry pi. Use cloud computing, the sensed information is eventually available on the cloud, and IoT to manage the pipeline's water flow. The core controller measures the perceived values. As the core controller for this project, Raspberry pi is used. Finally, monitoring and controlling via phone is observed using the IoT module's Wi-Fi.

\section{Methodology}

The project is divided into four phases. The first phase is integrating sensors with NodeMCU in the circuit. Next, the phase 2, developing the monitoring system using Blynk software. Meanwhile, phase 3 is developing a controlling system using the Blynk. Lastly, phase 4 overall review of the device development for the project.

Figure 1 shows the overall flowchart of the project. The project was carried out step by step. It starts by selecting the right device in developing an IoT-based microcontroller. Blynk software is used to develop the system and phpMyAdmin is used as cloud storage to store all the data. The interface is developed using Blynk software. After the system for monitoring the parameters succeed, the next phase of the controlling system is executed. Using the same software, Blynk is used to control the opening and closing of the water tap. After all the circuit properly works, the body of the device has been developed.

The sensors that have been used in this project are a $\mathrm{pH}$ sensor and a water temperature sensor. The $\mathrm{pH}$ sensor needs to be calibrated first before both sensors are integrated into the circuit. The power supply for the $\mathrm{pH}$ sensor needs to as close as possible to $5 \mathrm{~V}$. Adjusting the power supply is crucial to get the right $\mathrm{pH}$ value from the sensor. Once the $\mathrm{pH}$ sensor manages to get more or less the buffer solutions' value, the next step will be to integrating the sensors in the circuit.

The sensor has been connected with NodeMCU. Since NodeMCU ESP8266 V3 already includes a new pin where $\mathrm{VV}$ can supply $5 \mathrm{~V}$, the $\mathrm{pH}$ sensor can directly connect with it without any voltage regulator. Analog and VDD pin for $\mathrm{pH}$ sensor connected to $\mathrm{A} 0$ and $\mathrm{VV}$, respectively. The temperature sensor only needs a $3 \mathrm{~V}$ power supply that NodeMCU provides three pins with that feature. Before that, the sensor's data and VDD pin connected to the $4.7 \mathrm{k}$ ohm resistor because it does not have its power supply. Then VDD is connected to the D2 pin. Figure 2 shows the circuit connection of NodeMCU, pH sensor, and temperature sensor.

The next step is to develop a real-time monitoring system using the IoT-based microcontroller. The widget of labeled value and superchart at the Blynk widget box was created. After creating the Blynk account, Auth Token is sent through email, which acts as a unique ID for all users to connect their hardware with Blynk apps. Assigning different pin values for $\mathrm{pH}$ and temperature, then uploading the coding together with Wi-Fi ID, password, and Auth Token. If the result after the code is run does not display as instructed, troubleshoot and edit it. If the correct output is displayed, the data can be monitored through the user's mobile phone 


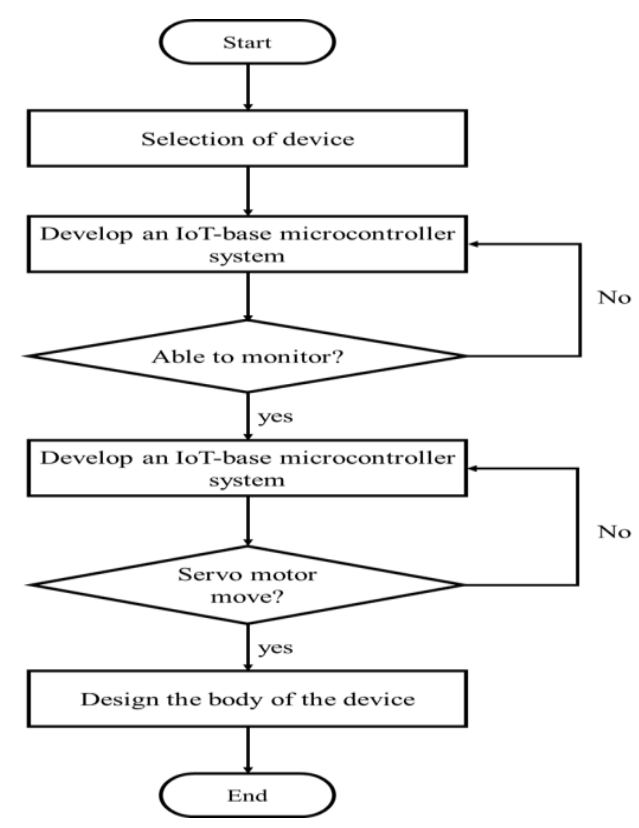

Fig. 1 - Overall flowchart of the project
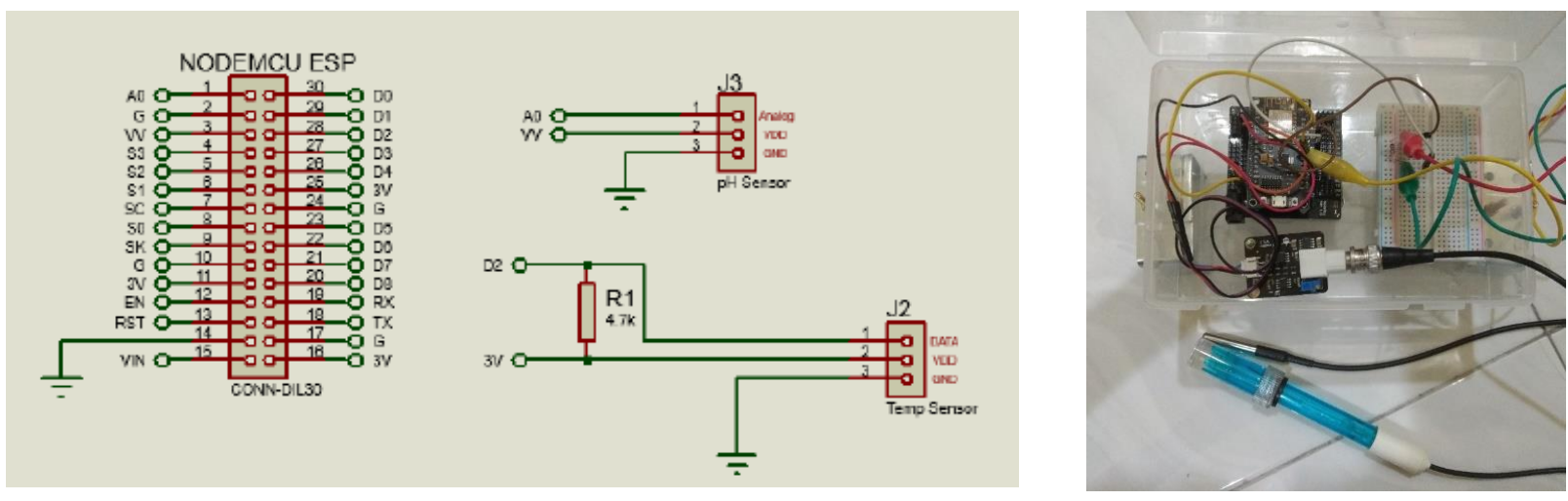

Fig. 2 - Circuit connection of NodeMCU, pH sensor and temperature sensor

A labeled value widget is used to monitor the current value of the temperature and $\mathrm{pH}$ at that particular time. In contrast, superchart widget is used to monitor the present and past data. User can see the trend for each data. All data need to be a push with the desired interval from the data.

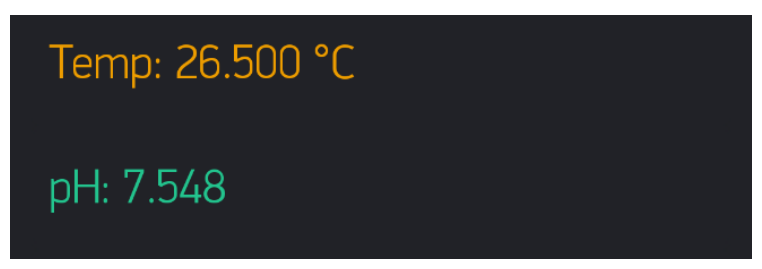

Fig. 3 - Labeled value widget of the device

Figure 3 shows the value that is displayed by the labeled value widget. To ensure the values are displayed, pin V2 and $\mathrm{V} 3$ are assigned for temperature and $\mathrm{pH}$, respectively. Figure 4 shows the coding of the labeled value widget that has been written in Arduino IDE.

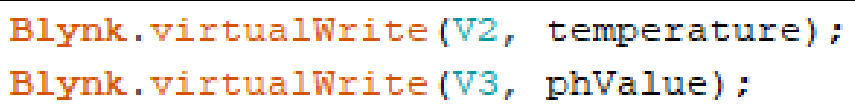

Fig. 4 - Coding for labeled value widget 
There are two superchart widgets created for $\mathrm{pH}$ and temperature value. Users can switch between time ranges and live mode. Time ranges can be adjusted by doing it at the setting. For this project, the time ranges being chosen are for every 30 minutes, every day, every week, and two weeks. The resolution allows the data to be more precise and accurate. As for saving the data, Blynk does not have a cloud storage feature. So, phpMyAdmin is used to collect all the data that has been monitored. The 000webhost is the server to connect Arduino IDE with the phpMyAdmin database. The data sent concurrently to Blynk and 000webhost and will allow the user to check back all the previous data and download it if they need it.

For control, a two-button widget was created to control the movement of a servo motor. The servo motor is controlling the water tap for the tank that holds the alkaline water. The button controls the time for the water tap opening. Coding is written using the same method with a monitoring system with the same Wi-Fi ID, password, and Auth Token. The coding is PUSH mode. Figure 5 shows the button widget.

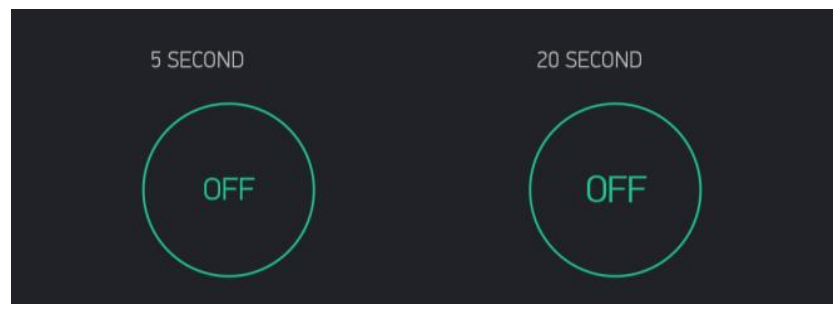

Fig. 5 - Button widget of the device

Pin V5 and V6 are assigned for the servo motor. Each pin opens the water tap for 5 seconds and 20 seconds, respectively. Figure 6 shows the coding for controlling the water tap in this project. Table 1 shows the effect of moving a servo motor in 5 seconds and 20 seconds.

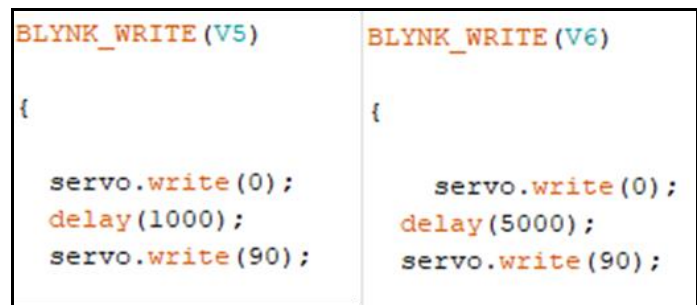

Fig. 6 - Coding for a button widget

Table 1 - The effect after moving servo motor

\begin{tabular}{ccc}
\hline Time & Quantity of Water & Effect \\
\hline 5 seconds & $10 \mathrm{ml}$ & Increase $\mathrm{pH}$ level up to 1 \\
20 seconds & $40 \mathrm{ml}$ & Increase $\mathrm{pH}$ level up to 2 \\
\hline
\end{tabular}

\section{Results and Discussions}

The first step is testing the temperature and $\mathrm{pH}$ sensor with different water and temperatures. Hot and cold water ranging from $25^{\circ} \mathrm{C}$ to $50^{\circ} \mathrm{C}$ is used to ensure that it can function well. As for $\mathrm{pH}$ sensors, buffer solutions of different values of $\mathrm{pH}$ from acid to alkaline. Figure 7 shows some of the results in testing the $\mathrm{pH}$ and temperature of the water.

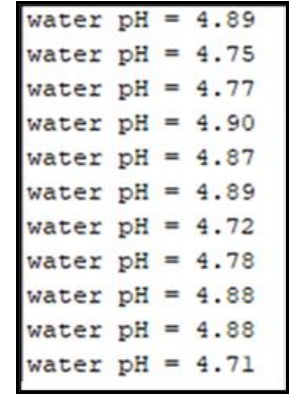

(a)

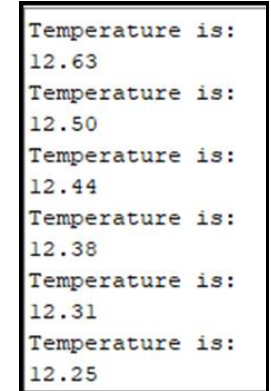

(b)

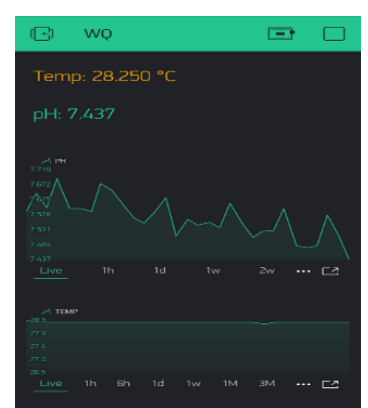

(c)

Fig. 7 - Result for testing (a) pH sensor; (b) Temperature sensor; (c) Blyk App 
During the testing, the Blynk app is run and opened to see live data view of the tank's water temperature and $\mathrm{pH}$ level. Figure 3 shows the current temperature and $\mathrm{pH}$ level during the testing period, $28.25^{\circ} \mathrm{C}$ and 7.437 , respectively. The table indicates that the optimum range for the temperature range is between $25^{\circ}$ and $29^{\circ} \mathrm{C}$, and the $\mathrm{pH}$ level range is from 6 to 9 .

At the same time, data is sent to the database in phpMyAdmin. One data is inserted in 50 seconds approximately. The time to insert data also depends on the internet connection. Some data will be a delay when the internet connection is weak and will affect the other data time because the data is inserted one at a time. The data will go back to normal after a while when the internet connection recovers. The time delay does not affect too much because the delay usually does not exceed 1 minute. Figure 8(a) shows the table in the database of real-time data. Figure 8(b) shows the data that is downloaded in CSV form, opened with Microsoft excel.

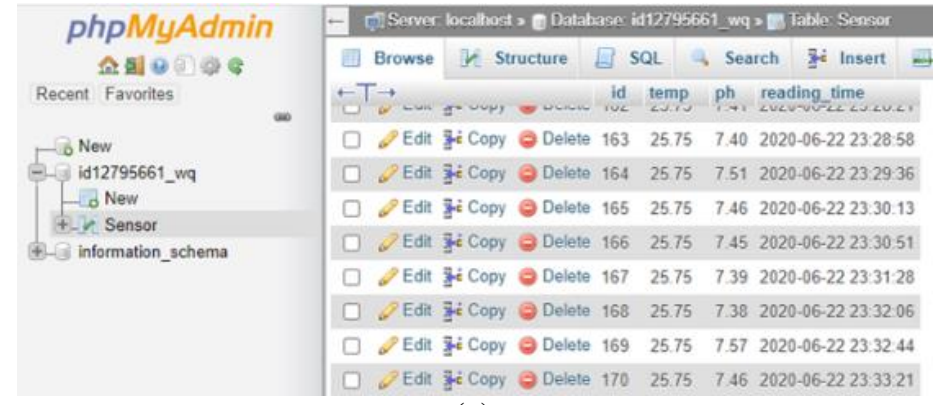

(a)

\begin{tabular}{|c|c|c|c|c|c|c|}
\hline \multicolumn{2}{|c|}{ S65 } & $\vdots$ & $\checkmark$ & $f_{x}$ & \multirow[b]{2}{*}{ D } & \multirow[b]{2}{*}{$\mathrm{E}$} \\
\hline 4 & A & B & C & & & \\
\hline 52 & 129 & 25.69 & 7.47 & $22 / 6$ & $/ 202023: 07$ & \\
\hline 53 & 130 & 25.62 & 7.51 & $22 / 6$ & $/ 202023: 08$ & \\
\hline 54 & 131 & 25.62 & 7.43 & $22 / 6$ & $/ 202023: 08$ & \\
\hline 55 & 132 & 25.69 & 7.52 & $22 / 6$ & $/ 202023: 09$ & \\
\hline 56 & 133 & 25.62 & 7.44 & $22 / 6$ & $/ 202023: 10$ & \\
\hline 57 & 134 & 25.69 & 7.46 & $22 / 6$ & $/ 202023: 10$ & \\
\hline 58 & 135 & 25.69 & 7.44 & $22 / 6$ & $/ 202023: 11$ & \\
\hline
\end{tabular}

(b)

Fig. 8 - (a) Data in phpMyAdmin; (b) Data in MS Excel

The controlling system is used when the water $\mathrm{pH}$ level is lower or higher than normal. In this testing, the indicator for normal water $\mathrm{pH}$ range is from 7 to 8 , while lower or higher than that will trigger the notification widget. Notification will be a pop-up on a user's mobile phone. Figure 9 shows the example when a notification occurs to a user's mobile phone. Users will be more aware of it and can open Blynk apps right away after the notification.
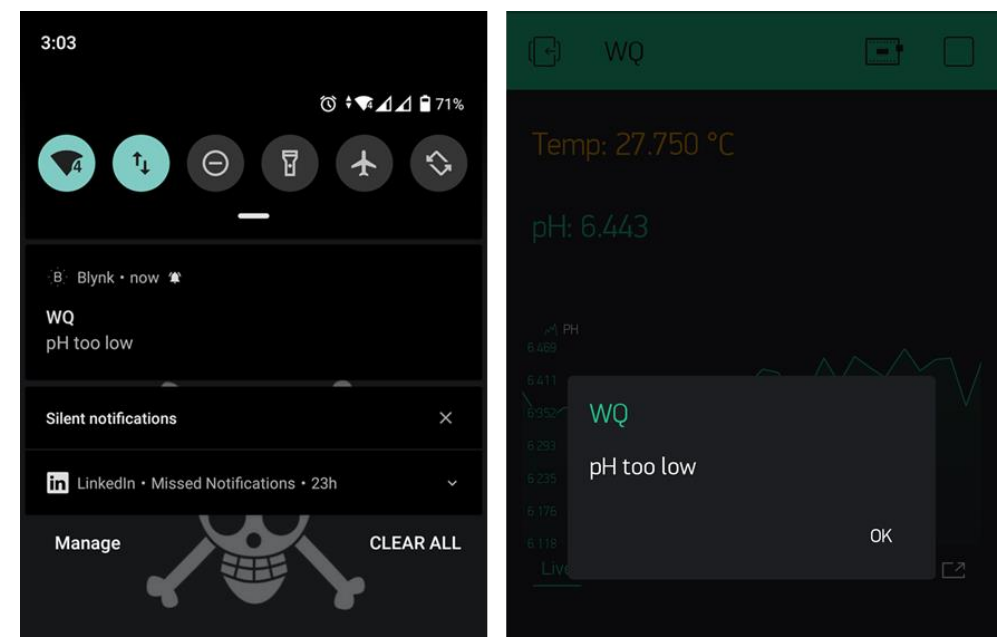

Fig. 9 - Notification on user mobile phone

Process in increasing water $\mathrm{pH}$ level takes about one minute approximately, but it depends on how many level. Controlling from distance help user to save time and energy to control water pH level. Figure 10(a) shows the change in the $\mathrm{pH}$ level of the water. The graph on the superchart widget shows the curve during the increasing period. Figure 10(b) shows how the $\mathrm{pH}$ level becomes neutral again after a while. 


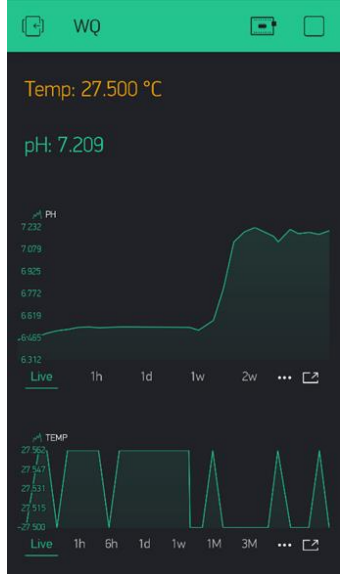

(a)

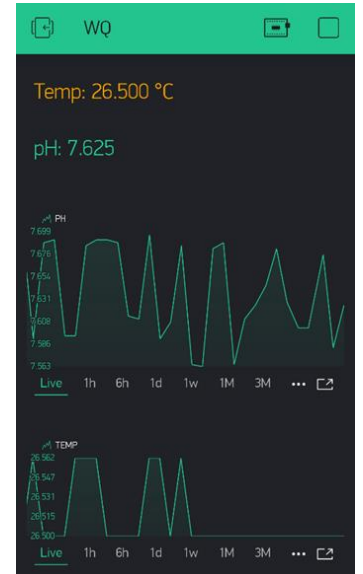

(b)

Fig. 10 - (a) pH level increase; (b) pH level back to normal

\section{Conclusion}

In conclusion, a system has been developed for monitoring and controlling water quality using IoT. Each part and module developed in the system functions properly: $\mathrm{pH}$ sensor, temperature sensor, and servo motor interfaced with NodeMCU ESP8266 seamlessly. Data from the sensor can be successfully monitored live using Blynk, and all the data is saved in the cloud database, which is phpMyAdmin. The user also can see the data trend by the graph generated by Blynk. Increasing $\mathrm{pH}$ level gives a user the control for water quality.

\section{Acknowledgment}

The authors would like to thank Universiti Tun Hussein Onn Malaysia (UTHM) for funding this research.

\section{References}

[1] Zainudin, Z. (2010). Benchmarking river water quality in Malaysia. IEM Jurutera, pp. 12-15

[2] Latest Pasir Gudang pollution caused by Sungai Kim Kim toxic waste. https://www.channelnewsasia.com/news/asia/pasir-gudang-air-pollution-toxic-waste-johor -sungai-kim-kim. last accessed 15/08/2020

[3] Enviromental Quality (Sewage) Regulation 2019, Jabatan Alam Sekitar, Kementerian Alam Sekitar dan Air

[4] Microbiological Water Pollution, https://www.water-pollution.org.uk/microbiological-water-pollution/, last accessed 31/07/2020

[5] Santoso, L. W., Kwariawan, A., \& Lim, R. (2017). IoT for real-time data logger and pH controller. In Proceedings of the 2nd International Conference on Culture Technology, Tokyo, Japan

[6] Das, B., \& Jain, P. C., (2017). Real-time water quality monitoring system using Internet of Things. IEEE International Conference on Computer, Communications and Electronics (Comptelix), pp. 78-82

[7] Kamaludin, K. H., \& Ismail, W. (2017). Water quality monitoring with Internet of Things (IoT). In 2017 IEEE Conference on Systems, Process and Control (ICSPC), pp. 18-23)

[8] Gopavanitha, K., \& Nagaraju, S. (2017). A low-cost system for real-time water quality monitoring and controlling using IoT. in 2017 IEEE International Conference on Energy, Communication, Data Analytics and Soft Computing (ICECDS), pp. 3227-3229

[9] Perumal, T., Sulaiman, M. N., \& Leong, C. Y., (2015). Internet of Things (IoT) enabled water monitoring system. In 2015 IEEE 4th Global Conference on Consumer Electronics (GCCE), pp. 86-87

[10] Qin, Y., Alam, A. U., Pan, S., Howlader, M. M., Ghosh, R., Hu, N. X., \& Deen, M. J. (2018). Integrated water quality monitoring system with $\mathrm{pH}$, free chlorine, and temperature sensors. Sensors and Actuators B: Chemical, $255,781-790$ 